\title{
Current Situation Analysis and Countermeasure Research of China's Innovative Human Resource Allocation
}

\author{
Jing LIU ${ }^{1}$, Yi ZHOU 2,a, Lijia HUANG ${ }^{3}$ \\ 1 Jiangxi Normal University Business College, China \\ 2 Jiangxi Normal University Business College, China \\ 3 Jiangxi Normal University Science and Technology College, China \\ a jxsdjh@vip.sina.com
}

Keywords: Innovative human resource allocation, Current situation analysis, countermeasure research.

\begin{abstract}
The economic development of a country depends largely on the level of innovation and development of the country. Innovative human resources are also a necessary condition for the implementation of the national innovation-driven development strategy. The rationality of its configuration directly affects the innovation capability and innovation efficiency. At present, China's innovative human resource allocation has the problems of insufficient input intensity, large regional differences, weak basic research, and vague corporate status. On the basis of reviewing the theoretical research results and practical exploration experience of innovation resource allocation at home and abroad, this paper is guided by the theory of innovation resource allocation, from the sound talent cultivation mechanism, narrowing regional investment differences, increasing basic research input, and strengthening the main body position of enterprises. Four aspects propose countermeasures to optimize the allocation of innovative human resources in China.
\end{abstract}

\section{Introduction}

Innovative human resources refer to laborers who are distributed among innovation entities such as enterprises, governments, universities, and scientific research institutions, who invest in innovative activities and form the basis of innovative activities, and participate in innovative subjects on new knowledge, new products, new methods, The formation and creation of new processes, etc., is the dominant force in creative activities and plays a fundamental and decisive role in innovation activities. At present, the common indicator used to measure the amount of innovative human resources in a country is the number of research and development activities, mainly including those engaged in three types of innovation activities: basic research, applied research and experimental development.

\section{Analysis of the current situation of innovative human resource allocation in China}

\subsection{Overall configuration}

From 2006 to 2016, China's innovative human resources showed an overall upward trend, and the increase rate gradually slowed down after 2014. In 2016, there were 5,380,700 R\&D personnel in China, including 2,608,200 undergraduate students, accounting for 44.73\%; the number of master's graduates was 845,900 , accounting for $14.51 \%$; the number of doctoral graduates was 378,800 , accounting for $6.50 \%$; females were $1,545,200$, accounting for $26.50 \%$. In 2016, the total number of R\&D personnel in the country was $3,878,100$. The researchers were 169.22 person-years, accounting for $43.83 \%$ of the full-time equivalent of personnel. By 2016, the full-time equivalent of R\&D personnel was 2.6 times that of 2006, indicating that China's innovative human resources have achieved a significant increase in the total amount. 


\subsection{Main configuration}

In 2016, the R\&D personnel of China's R\&D personnel invested in the total industrial enterprises above designated size of 27.025 million, accounting for $69.69 \%$; the research institutions invested $390,100,000$ years, accounting for $10.06 \%$; the investment in colleges and universities was 360,000, accounting for 9.28 . \%; invested in other 415,400 person-years, accounting for $10.97 \%$. The data shows that China's R\&D personnel are also mainly invested in enterprises, and scientific research institutions and institutions of higher learning account for a relatively small proportion. In particular, it should be pointed out that compared with 2006, the proportion of R\&D personnel invested in enterprises increased from $46.34 \%$ to $69.69 \%$; the proportion of scientific research institutions and universities decreased from $15.38 \%$ to $10.06 \%$ and $16.11 \%$ to $9.28 \%$, indicating that The main status of Chinese enterprises has been established.

\subsection{Stage configuration}

In 2016, the R\&D personnel's full-time equivalent investment in China was 274,700,000 years, accounting for $7.08 \%$; the applied research was 438,900 , accounting for $11.32 \%$; the experimental development was 3.164 million, accounting for $81.60 \%$. The data shows that the configuration of $\mathrm{R} \& \mathrm{D}$ personnel in China between the innovation stages is mainly invested in experimental development. Basic research and applied research account for a very small proportion. Compared with 2006, the proportion of R\&D personnel investing in basic research in China decreased slightly; the proportion of input to applied research decreased from 19.95\% to $11.32 \%$; on the contrary, the proportion of input to experimental development increased from $71.31 \%$ to $81.60 \%$, indicating that China will The vast majority of R\&D personnel have invested in the development of the experiment. From 2006 to 2016, the trend has been on the rise. In contrast, the applied research has declined, and the basic research has been running smoothly.

\subsection{Area Configuration}

In 2016, the total time equivalent of R\&D personnel in China was 3,878,100, and the eastern, central, western and northeastern regions had 254.52, 65.28, 48.90 and 191,000, respectively, accounting for $65.63 \%, 16.83 \%, 12.61 \%$ and 4.93 respectively. \%. The proportion of R\&D personnel in the eastern region is much larger than that in the central region, the western region and the northeast region. It can be seen that the allocation of innovative human resources in China varies greatly in different regions. And R\&D personnel are concentrated in Guangdong, Shandong, Zhejiang, Jiangsu and other places. Among them, R\&D personnel ranked first in Jiangsu, second in Guangdong and third in Shandong; researchers ranked first in Jiangsu, second in Guangdong, and third in Beijing; the investment in trial development ranked first in Jiangsu and second in Guangdong. Zhejiang third. The data shows that innovative human resources in Jiangsu and Guangdong are abundant, while innovative human resources such as Xinjiang, Qinghai, Ningxia, Gansu and Hainan are weak.

\section{Existing problems in the allocation of innovative human resources in China}

\subsection{Insufficient input strength}

China's investment in innovative human resources increased by 150.687 billion yuan, an increase of $10.6 \%$, and the growth rate was 1.7 percentage points higher than that of the previous year; the proportion of undergraduate graduation was the largest. Overall, the proportion of men is greater than the proportion of women. Compared with 2006, China's total investment in innovative human resources has grown rapidly. Although China's R\&D investment has steadily increased this year, compared with the strength of science and technology innovation and the input intensity of innovative personnel, the level of input intensity of R\&D personnel in China is relatively low. In order to realize the effective allocation of innovative resources, China needs to further increase the total amount. Increase the input intensity of innovative personnel and improve the quality of innovative human resources. 


\subsection{Regional differences are large}

It can be found that the proportion of innovative human resources invested in the eastern region is much larger than that in the central region, the western region and the northeast region, concentrated in Guangdong, Shandong, Zhejiang, Jiangsu and other places, and innovative human resources like Xinjiang, Qinghai, Ningxia, Gansu and Hainan. weak. Relevant information shows that the difference in innovation human resources investment between the industries is also significant. The regional and industry innovation human resources investment is relatively insufficient, which restricts the improvement of the efficiency and technological progress of its innovative human resource activities, thus affecting the effective allocation of its innovative human resources.

\subsection{Basic research is weak}

The data show that the proportion of R\&D investment in China for basic research and experimental development is significantly less, especially basic research, and the proportion of experimental development has increased significantly. On the other hand, China only pays attention to the immediate achievements, and the basic research is exploratory and long-term. It has considerable complexity and great difficulty. It will invest most of it in experimental development and does not see long-term benefits. Funding for basic research and applied research is not valued, making the promotion of innovative resource allocation capabilities for basic and applied research significantly less than experimental development.

\subsection{Fuzzy corporate status}

Although from the perspective of the source structure of innovative human resources input, the innovative human resources investment of enterprises has an absolute dominant position, which cannot indicate that China's innovative human resources investment has entered the enterprise-led mode. The innovative human resource investment model of Chinese enterprises has not yet been effectively formed. Compared with developed countries, this will be a protracted war. There are many factors that influence the establishment of the enterprise-oriented innovative human input model. For example, the size of the enterprise, whether it is a high-tech enterprise and the ability of entrepreneurs to innovate, it also has a greater impact on the efficiency of China's innovative human resource allocation.

\section{Research on the countermeasures of optimizing human resources allocation in China}

\subsection{Improve the talent cultivation mechanism}

We will strengthen investment in innovative human resources as soon as possible, improve the current situation of serious brain drain, and curb the adverse conduction effects caused by the decline in investment in innovative talent resources on the efficiency of resource allocation in regional innovation systems. First, we must establish an effective talent flow mechanism. Second, we must establish an open talent introduction mechanism. At the same time, we must accelerate the reform of the education system and establish a talent training mechanism based on comprehensive quality education and with innovation consciousness as the core.

\subsection{Reducing regional input differences}

The investment in innovative human resources between different regions is far from the same, and the contradictions in regional economic development are deepening. This is the coordination of China's economy. Sustained development has created enormous challenges. The government should actively play its regulatory role and rationally allocate innovative human resources among different regions. At this stage, the government should firmly support the less developed regions of the central and western regions, increase investment in innovative human resources, and guide the investment of $\mathrm{R} \& \mathrm{D}$ personnel in enterprises, thereby improving the ability of innovative resource allocation throughout the country. 


\subsection{Increase investment in basic research}

In fact, basic research and applied research have a great role in promoting the ability of innovative resource allocation. Basic research and applied research will play a greater role in promoting the improvement of innovative human resource allocation capabilities. Therefore, it is necessary to strengthen the R\&D investment in basic research and applied research in all regions of the country, so that the input of innovative human resources at all stages is more rationalized, thereby improving the unbalanced status of innovative human resources investment in basic research, applied research and experimental development.

\subsection{Strengthening the position of the company}

China must make innovative human resources investment better translate into innovative output to increase the economic benefits brought by innovative activities. Enterprises can use the window of universities and research institutes to complete the process of product development from research and development to the process of cooperation in innovation activities with universities and research institutions to create economic benefits and promote economic development. At this stage, China should speed up the establishment of an innovation system that combines production, study and research with enterprises as the main body, strengthen the innovation capability of enterprises, and increase investment in research and development of universities and research institutions, so that all subjects can allocate resources reasonably and play the biggest role.

\section{Summary}

In today's social and economic integration, innovative human resources are not only an important indicator of economic growth and social development in a certain region or even the whole country, but also an important measure to measure its comprehensive strength and development potential. However, at present, many problems exist in the allocation of innovative human resources in China. Only through the cooperation of the government and enterprises, the innovative human resources can be effectively integrated and play its role, in order to optimize China's innovative human resource allocation and achieve maximum economic benefits.

\section{Acknowledgement}

This paper is one of the research results of Research on the Difference of Enterprise Innovation Resource Allocation System under Supply Side Reform in the Research project of Humanities and Social Sciences in Universities in Jiangxi Province.It is funded by The Special Fund for the Visiting Scholars of the Young and Middle-aged Teacher Development Program in Jiangxi Ordinary Universities.

\section{References}

[1] Y. Li and Y.P. Wang, Government R\&D funding crowding out effect and innovation efficiency under institutional constraints, Research Management, vol.36, pp. 58-65,2015.

[2] J.W. Tan and L. Ye, valuation of regional collaborative innovation human resources support system: Chongqing example, Research Management, vol.37, pp. 659-667, 2016. 